\title{
Veterinarians are Paid to Make Decisions
}

\author{
Carlos Tadeu Pippi Salle* \\ Department of Veterinary Medicine, Brazil \\ *Corresponding author: Carlos Tadeu Pippi Salle, Faculty of Veterinary Medicine, Federal University of Rio Grande doSul, Brazil
}

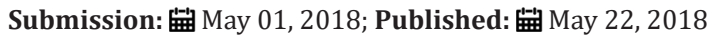

\section{Opinion}

Decisions taken without objective criteria are not decisions, they are hunches. Some years ago, mathematical models have been developed in our laboratory to help explain the immune response to vaccination programs and understand the damage caused by mycotoxins (highly carcinogenic fungal toxins) in chickens. It was also developed a methodology for the use of artificial intelligence (artificial neural networks) to manage the phenomena that involve this segment of the industry in several stages of production.

The studies are original and have been published in scientific journals of national and international renown. All of the above studies cited were performed with the participation of some Brazilian poultry companies, which provided the data (inputs) and allowed the analysis of their production data records. We concluded that artificial neural networks were able to explain the phenomena involved among the four stages of poultry production, breeders, hatchery, broiler production and slaughterhouse. The method allows making predictions and simulations for risk management. This technique proves scientifically that we can create objective criteria, and this methodology becomes an important tool in making decisions taken by managers of these important sectors of the poultry chain. Also in the area of artificial intelligence, researches have been developed for the digital processing of images and emission of histological diagnosis with the use of artificial neural networks.

This new process was called Digital Analysis of Lymphoid Depletion (ADDL). Desirous of promoting the availability of modern technology to professionals that work in the field and in slaughterhouses, our laboratory is developing some studies for the molecular characterization of pathogens. For instance, 38 genes associated with the virulence of Escherichia coli have been identified and were able to determine its pathogenicity, injury induction, biochemical properties and antimicrobial resistance.

The results were analyzed using artificial neural networks and answered to two basic questions: the first is "is the isolated strain pathogenic?" and the second, "how should I treat the animals? "Currently, the characterization of genes associated with virulence indicates the potential damage to the host, but it does not indicate what really matters, i.e., the expression of these genes in terms of pathogenicity and antimicrobial resistance. Our method responds to both questions and it will have repercussions on animal health and public health. Subsequently, we classified the same strains into different phylogenetic groups, because it is a simpler and cheaper method to be performed in routine monitoring. New studies are underway and the same artificial intelligence methodology is used to determine pathogenicity and antimicrobial resistance to antibiotics to some Salmonella sero types and to Pasteurella multocida.

Combining the results of mathematical models of the immune response, the influence of mycotoxins on production parameters, ADDL, the use of artificial intelligence to classify the pathogenicity and antimicrobial resistance of Escherichia coli, it has developed a risk analysis system that allows the regionalization of health status of different flocks of an integration, through objective and scientifically established criteria (Figure 1). A clear understanding of the criteria will facilitate the desired understanding between government and private sector. All of these studies have been developed over a period of 15 years and they can be used both by the Ministry of Agriculture, Livestock and Food Supply and by the Ministry of Health of the countries as well as by the poultry industry. Finally, the training programs will allow professionals to be able to use the methodology proposed as support for decisionmaking in the daily routine of poultry companies and government departments.

Figure 1: An example of the use of the proposed methodology. It exemplifies the regionalization of the health risks of a poultry integration. Different degrees of lymphoid depletion (ADDLs) can be evaluated in combination with different levels of Pathogenicity (PI) of Escherichia coli that infect the animals and their antimicrobial resistance. To these indicators are added the interpretation criteria of serological surveillance, the influence of mycotoxins on production parameters and studies on Salmonella. The collection and analysis of the data generated will lead to the development of objective and scientifically proven criteria to serve as a tool for decision support. All information can be on the packaging through the use of QR codes and the consumer using a smart phone will have instant access to them. 


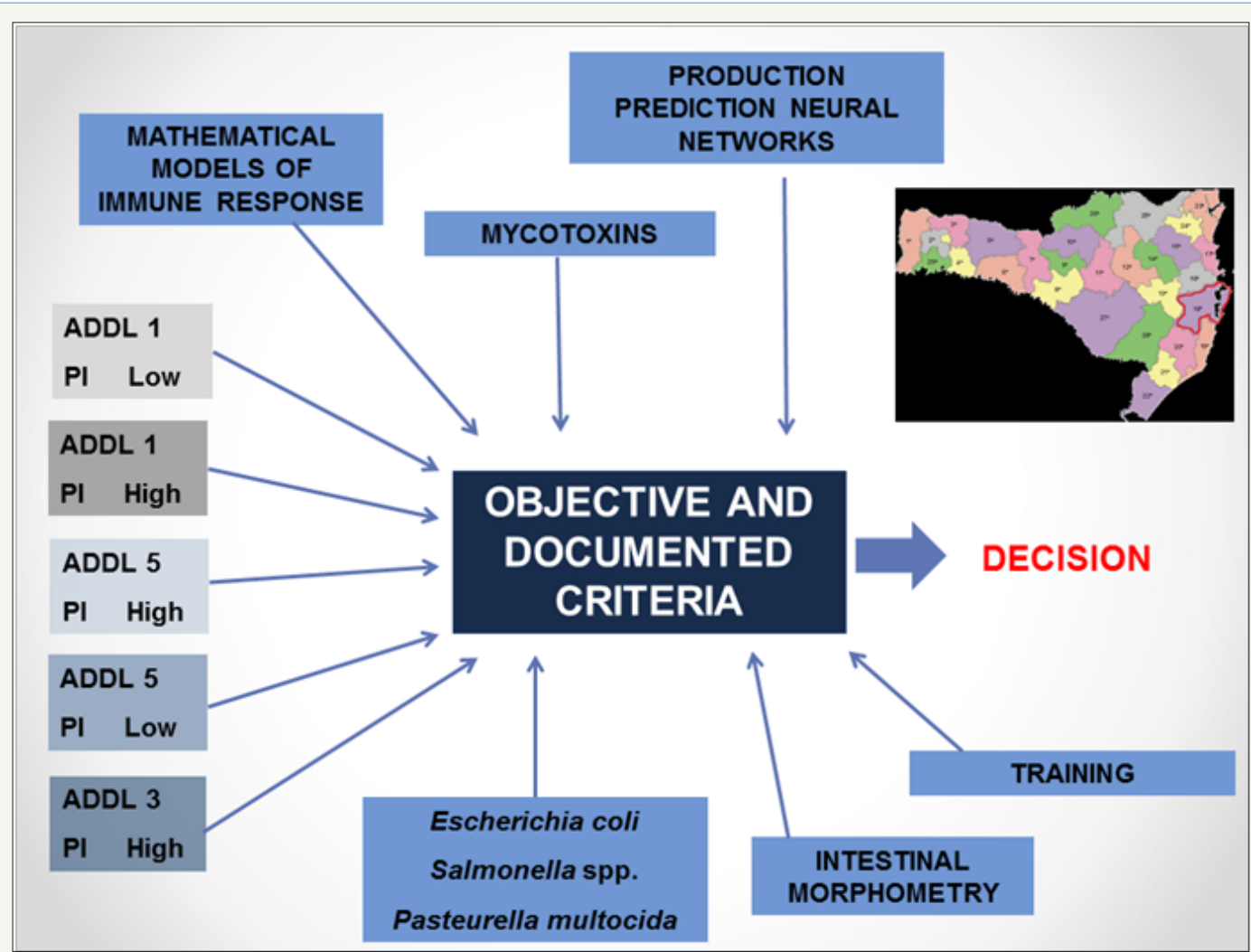

Figure 1: Example of decision making

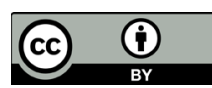

Creative Commons Attribution 4.0 International License

For possible submissions Click Here

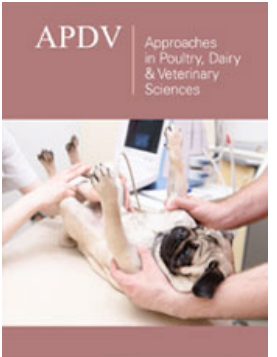

Approaches in Poultry, Dairy \& Veterinary Sciences

Benefits of Publishing with us

- High-level peer review and editorial services

- Freely accessible online immediately upon publication

- Authors retain the copyright to their work

- Licensing it under a Creative Commons license

- Visibility through different online platforms 